\title{
Structural factors and integrated care interventions: is there a role for economists in the policy debate?
}

\author{
Luke B. Connelly ${ }^{1} \cdot$ Gianluca Fiorentini $^{2}$ \\ Accepted: 28 November 2020 / Published online: 2 January 2021 \\ (c) Springer-Verlag GmbH Germany, part of Springer Nature 2021
}

\section{Introduction}

Concerns about the sustainability of health care expenditures in the face of advancing medical technology, widespread insurance, the aging of the population, and income growth have demanded that economists focus not only on the roles of these factors, but on ways of managing health care consumption and health investment better. Over the past few decades, integrated care (IC) has been emphasized as solution that promises to make the supply of health care more effective and efficient and for managing consumers' demands for services (for a recent, comparative analysis of the potential of IC, see [1]). Yet, as decades of empirical evidence now demonstrate, the more Panglossian predictions of IC's promise have been frustrated (see, e.g., [2, $3]$ ). Indeed, the weight of evidence from papers in the peerreviewed literature-across all relevant disciplines-demonstrates that IC interventions often have modest effects on their intended targets (for systematic reviews, see [4] and [5]). In this Editorial, we outline our thoughts on why the fruits of IC have often failed to be realized. We argue that a range of structural factors, that are not typically emphasized by non-economists who write on this topic, are the key to understanding how and why particular IC interventions tend to fail (or succeed). We emphasize the unique perspective and comparative advantage that economists can bring to bear on this topic by incorporating the role of systemic and institutional structures and the incentives that are inherent in them, as central to analyses of what types of IC are (un) likely to work. In particular, some of the structural elements

\footnotetext{
Luke B. Connelly
}

1.connelly@uq.edu.au

1 Centre for the Business and Economics of Health, The University of Queensland and Dipartimento di Sociologia e Diritto dell'Economia, Università di Bologna, Bologna, Italy

2 Dipartimento di Scienze Economiche, Università di Bologna, Bologna, Italy of extant health systems are more of the nature of constraints than fungible instruments of health policy.

Our objective is to develop an economic characterization of the microeconomic problems of different types of IC initiatives and their implementation, followed by a taxonomy of them that pertains directly to commonly observed differences in health system characteristics (which we label "macroeconomic" factors). We argue that interventions in the set referred to generically as "IC" are quite heterogenous and that between countries, and sometimes even within them, health systems are also characterized by considerable heterogeneity. Taking the latter as more-or-less exogenous, we seek to illustrate how these microeconomic and macroeconomic characteristics combine to make particular kinds of IC interventions more successful and more likely to be effective and sustainable in some health care systems than in others.

We are certainly not the first to point to the heterogenous nature of interventions that fall under the IC umbrella. In fact, we start out in Sect. 2 by providing a broad survey of IC interventions along with a non-economic taxonomy that classifies different types of IC interventions according to their clinical and demographic properties and the nature of the interventions themselves. We do this partly to introduce examples of IC interventions and evidence of their (in)effectiveness in various settings, but our primary purpose is to lay the groundwork for an analysis of how the substantive economic properties of IC interventions are likely to differ: not only according to intervention type, but also in the face of different institutional structures and incentives. Sections 3 and 4 set out what we regard as the key economic characteristics of IC interventions: we argue that these must be considered to understand their probable success or failure in any given setting. These economic characteristics pertain both to health care financing and the delivery of health care. Chiefly, they concern the combined influences of: (i) market structure (competitiveness); (ii) organizational integration (vertical and horizontal); (iii) pecuniary and non-pecuniary incentives; (iv) fixed and sunk costs of IC investments; and (v) 
externalities (or "appropriability" problems) on consumer and producer behavior. In Sect. 5, we develop a microeconomic taxonomy of IC interventions and their effectiveness, drawing on our arguments in the preceding Sections. We then overlay a macroeconomic taxonomy in which we seek to characterize the strength with which the microeconomic problems are likely to be most acute for different types of IC interventions in different health care systems. In Sect. 6, we ask whether it is possible to test our conjectures, empirically, on the existing evidence. We argue that a number of problems frustrate this kind of undertaking so badly as to render any conclusions that might be drawn a relatively weak basis for policy evaluation. Instead, we set out the likely problems of different IC interventions in various settings and make conceptual arguments as to what economic theory predicts will and will not work, based on our overall taxonomy. Section 7 presents our conclusions and some implications for the role of economists in health policy development.

\section{A broad survey of integrated care models}

IC is a term that has been used to refer to a very broad range of interventions that have the purpose of improving the way that care is either coordinated or delivered. Valentijn et al. [6] developed a taxonomy of IC, starting from the viewpoint that primary care is an integral part of IC interventions (also see [7]). Their conception begins with the observation that IC involves attempts to improve "connections" between different parts of the health care and social systems that influence people's health. The taxonomy they develop contains eight types of integration, all of which concern the processes via which IC "connections" can be made. Specifically, they refer to:

1. Strategies that link similar levels of care ("horizontal integration");

2. Strategies that link different levels of care ("vertical integration");

3. The alignment of rules and policies within a system ("system integration");

4. The extent of coordination of services across different institutions ("organisational integration");

5. The extent to which professionals from different disciplines coordinate services across disciplines ("professional integration");

6. The extent to which clinical care services are coordinated ("clinical integration");

7. The extent to which "back-office" and support functions are coordinated ("functional integration"); and

8. The extent to which a mission, work values, and so on are shared within a system ("normative integration").
First, note that their first two categories, along with the last one, are labeled in a way that differs from the conventional economic use of these terms. In economics, horizontal and vertical integrations refer unambiguously to outcomes of the "make-or-buy" decisions of firms, but the definitions applied by Valentijn et al. [6] do not suggest that physical (or structural) integration is necessarily involved: "strategies" implies a broader set of activities that need not involve structural changes. The use of the term "normative" by Valentijn et al. [6] appears to accord with that term's common use in epidemiology: Epidemiologists typically use the term normative to refer to phenomena or "... data that characterize what is usual in a defined population, at a specific point or period of time" ([8], p.307). ${ }^{1}$ In economics and philosophy, by contrast, the positive/normative distinction is commonly used to invoke the distinction between statements that are empirically verifiable (falsifiable), and those that contain value judgements (and hence are not verifiable/falsifiable). (For a discussion and critique of the latter tradition, see, e.g., [10] and [11]). Nevertheless, the Valentijn et al. [6] taxonomy - which is based on a scoping review of the IC literature-provides a useful way of thinking about "what" is to be integrated and (broadly) how, in different types of IC interventions. More generally, it provides a general picture of the heterogeneity of interventions that is captured by the umbrella-term "IC", and hints at the different economic considerations that may be involved in these different types of integration as a result.

The further distinction that Valentijn et al. [6] emphasize concerns the way that different types of integration are required depending on the target patient population. They distinguish between micro-, meso-, and macro-levels of integration that increasingly move from being patient-focused to population-focused IC initiatives. For instance, patientfocused integration (e.g., clinical integration) occurs at the micro-level, while other forms of integration also depend on the integration of organizations (at the micro- and mesolevels), while functional and normative integration must occur at each of these three levels to be complete.

The taxonomy produced by Valentijn et al. [6] was not expressly designed to consider the economic consequences of the different types of innovation that may be called for in a particular IC intervention, nor what bearing the extant institutional or systemic arrangements may have on the relative costs and benefits, or likelihood of success of any particular IC initiative (see, however, [12] and especially [13] for insightful discussions from the medical literature on the structural problems that affect IC interventions). To economists, though, it must be clear that the spectrum of

\footnotetext{
${ }^{1}$ See [9] for a more recent discussion of normative data in epidemiology.
} 
interventions-which extends all the way from exhortations to adopt and follow clinical guidelines and education programs for clinicians or patients (which carry no structural implications), through to redesigning payment systems and incentives, vertically integrating doctors and hospitals, and so on, and may involve fairly radical changes to structures and payment mechanisms - also entails a spectrum of economic considerations, to which we now turn our attention.

\section{The role of market structure, sunk costs and externalities}

In this section, we provide a discursive overview of some economic considerations that are of central importance when considering the likely effectiveness and sustainability of different types of IC initiatives. We do this as the preliminary step for establishing the micro- and macroeconomic taxonomies that are developed in Sect. 5.

Market structure-in the traditional sense of industrial economics-is one of the most important considerations of how and why specific IC interventions may work well in one health care system and not at all, or in a limited way, in another. This is true both of the organization of health care services themselves, and of the competition on various parts of the (primary, secondary, and tertiary) provision markets, as well as of the competition (or otherwise) on the part of health care insurers or funders. Together with questions of vertical integration-which we discuss in the next section-these structural factors in the markets for insurance and health care services delivery are liable to have profound influences on the types of IC initiatives that succeed or fail. They also have direct bearing on the likelihood that the returns from innovations that improve health care efficiency and health outcomes are adequately internalized by those who initiate them.

One important aspect of market structure arises from health care financing arrangements. There are clear differences between systems in which there are multiple payers (e.g., the United States, the Netherlands, and Switzerland) and NHS-type systems (e.g., the UK, Italy, and Canada) in which there is a monopsony buyer of services. Private monopoly power is often, itself, a source of market failure [14]. Yet, monopsony buyers of health care services may also have economic advantages over competitive buyers of health care services for a variety of reasons. National, compulsory, and universal NHS-type systems do not, by definition, face the adverse selection problem (since the population is enrolled); moreover, a (protected) monopsony buyer's investments to improve population health cannot be competed away over time. Thus, the present value of the benefits of costly investments to integrate health care, engage in preventive initiatives, and so on is more likely to outweigh the substantive immediate costs of those investments than it is on a market where insurers compete with each other for insureds, to sell short-term (e.g., annual) policies. Moreover, monopsony buyers are able to exercise considerable power over the less-concentrated supply side of the market. Subject to political and other constraints, monopsony public buyers are more likely to be able to insist on the adoption of some innovations than are insurers that operate on a competitive insurance market. More generally, public monopolies, if run for the public good, will not follow the private monopoly approach to prices and quantities, but may adopt a Paretooptimizing approach to their activities.

Related to this point about market structure is the observation that some IC investments-such as the introduction of new information technology to streamline and better coordinate care for insureds-involve large and lumpy fixed costs, which are generally sunk. On competitive insurance markets, they often will also entail externalities [15] with public good [16] characteristics. Specifically, other private insurers may benefit from one insurer's investments to improve the efficiency of health care provision, billing, and so on. For instance, an insurer that introduces an efficiency-improving innovation-such as an investment in process innovations in service delivery and billing with health care providersmay create benefits that other insurers capture by free-riding (see, e.g., [17]). This, in turn, may create a tragedy-of-thecommons-type problem $([18,19])$ of under-investment in IC innovations: while the social benefits of some innovations may generate net social benefits, no individual firm may capture enough of those benefits to generate a positive private net present value (NPV) on investment. On competitive insurance markets, this problem may be exacerbated if insurers can profit by cream-skimming patients who are the beneficiaries of other insurers' investments. This may be as simple as offering lower premia from a lower cost base that is partly due to their own, strategic, under-investment in similar initiatives. While public subsidies, regulatory solutions, and so on are theoretically relevant ways to address this potential source of market failure, their use on the US market (for instance) has been sparing (see, e.g., [20]). There is also considerable evidence that the administrative costs and inefficiencies that arise on the US health care market result substantially from the multiple-payer problem (see, e.g., [21]).

\section{The role of vertical integration, remuneration, and incentives}

Another defining structural characteristic of different health care systems is (i) the extent to which health care provision itself is integrated, and (ii) whether or to what extent health care financing and provision are integrated. In NHS-style 
systems, the health care financing and provision roles are typically integrated: there is a large single payer that also is responsible for the delivery of health care. In many instances, the responsibility for the provision of care in such systems is devolved to sub-national entities such as regional or local health authorities, as is the case in the UK NHS and is generally true in Italy. This devolution of the responsibility for delivery to local areas may be viewed as a recognition of the fact that the markets for health care tend to be "local" in nature and the needs of the population are likely to vary across local areas. Yet, it is clear that the financing and provision roles are, fundamentally, integrated, even though provision responsibilities may be locally delegated. An important economic characteristic of these systems is that clinical labor is also vertically integrated: medical and other staff are (by and large) employed by the NHS and, subject to the market power of individual clinicians, essentially direct control is exercised over their clinical activities by the funder(s).

Thus, at least one of the important "make-or-buy" decisions that firms such as hospitals have to make when their funding is largely competitive (e.g., which clinical staff to employ directly) is largely decided in NHS-style health care systems. Thus, taking long-standing NHS arrangements as given (or as a "constraint"), some IC proposals that are raised in the US-focused literature are essentially not relevant in these systems. That is to say, structural integration is often imposed, by design, when health care financing and provision are integrated under NHS arrangements.

While structural changes in these systems are likely to be marginal in the short run, attempts to improve the other, non-structural, aspects of integration referred to by Valentijn et al. [6] nevertheless remain an important focus of policymakers (see, e.g., [22]). Furthermore, with a single payer and the integration of health care financing and delivery, longterm returns on investment are capitalized, with certainty, by the national payer. Without the threat of those returns being competed away, large socially optimal investments in IC are therefore more likely to be made, ceteris paribus, in NHS-style systems. Furthermore, the prospect of encouraging adherence to clinical guidelines for the treatment of people with chronic conditions, for instance, may be greater due to the monopsony power of the funder in these systems.

The latter point may be complicated by the institutional arrangements that affect how doctors and other clinical staff are paid. Under NHS arrangements, GPs tend to be paid on a capitation basis, specialists in the public hospital system are often salaried, and specialist ambulatory care may attract fee-for-service (FFS) payments, as is the case in Italy, for example. In other systems, like Australia's, while public hospital clinicians are paid on a salaried or sessional basis, most ambulatory care and much private specialist care is provided on a fee-for-service (FFS) basis. In that system,
FFS subsidies provided by the Commonwealth (i.e., federal) Government. Thus, not only are most GPs (for instance) not vertically integrated as they are in many NHS-type systems, they also face different incentives that may affect their propensity to follow specific treatment guidelines. Similarly, Australia has a large private hospital sector and a considerable proportion of the population holds private health insurance, and these aspects of the health care system may create similar types of problems to those we referred to earlier in the context of the United States.

An important general question is how these remuneration mechanisms and other incentives implied by institutional structures are likely to affect the alignment of doctors' incentives with those of their patients and those of the funder(s). Consider, for instance, disease-specific IC initiatives that are intended to improve the long-run management of chronic conditions (e.g., Type II Diabetes and Chronic Kidney Disease), thereby improving health capital by optimizing health services use. Following Blomqvist [23], if we conceive of doctors as utility-maximisers who also serve as dual agents of both the funder and the patient, how are differences in their integration and remuneration expected to affect their response to such initiatives? Capitation and FFS, as well as integrated and non-integrated employment arrangementsespecially in their various combinations-may have very different implications for the implicit strength of agency as between funders and patients. Vertically integrated GPs and specialists, for instance, may ceteris paribus be more readily subjected to monitoring or to the imposition of performance measures by the funder than their non-integrated counterparts.

Furthermore, even though performance monitoring may be possible even under FFS arrangements like those found in Australia, the funder agency of clinicians, who operate at arm's length from the funder, may be blunted and-without adjustments to the way that fee income is derived - their net incomes may be either favorably or adversely affected by adhering to specific guidelines.

In capitation systems, such as those in the UK and Italy, it is also true that patients can choose their practitioner. To this extent, it is to be expected that in more competitive regions (e.g., where there are more GPs per capita), the threat of patient-exit still carries implications for practitioner incomes. Yet, the balance between funder and patient agency would otherwise seem to be tilted more strongly in favor of the funder in vertically integrated systems, and more strongly in favor of the patient under less-integrated arrangements that are also dominated by FFS as the payment mechanism, ceteris paribus. It also seem, prima facie, that instituting new treatment guidelines under NHS-type arrangements is likely to carry lower transactions costs for the funder than those that are included under more competitive arrangements. 
Those transactions costs, too, are likely to be exacerbated when there are many funders as opposed to a monopsony funder.

Finally, in competitive markets-meaning those in which the insurance and care functions are largely not integrated-IC initiatives that call for structural change in the form of, say, vertical integration, also typically entail large sunk costs. Competitive pressures from non-integrated funders may lead them to innovate, and perhaps even to integrate the financing and provision functions in some instances. Yet, the same competitive pressures may, ultimately, lead them later to reverse their "buy" decision. Certainly, this situation has been witnessed in Australia, where several major private health insurers purchased hospitals in the late 1980s and early 1990s, subsequently divesting themselves of most of those investments (see, e.g., [24]). Similarly, variations in levels of integration are witnessed in different regions of some systems that are otherwise best characterized as "NHS"-type systems. For instance, in the Italian regional health authority of Lombardy, in Italy, health care production is less vertically integrated than in neighboring (and other) regions such as Emilia-Romagna. The former relies considerably more heavily on purchasing services from private providers as well as from its own network of public hospitals than does the latter, for instance, although in both instances, there are contracts with private providers.

There is some evidence that runs contrary to the general, heuristic account that we have offered vis-à-vis competitive and monopsony funder environments and integration decisions. Long-standing organizations such as Kaiser Permanente, in California, have offered integrated insurance and health care for decades, and there are also recent instances of US health care insurers purchasing their own primary care clinics [25]. These exceptions provide some further opportunities for insight, although the latter development is fairly recent. We speculate that, in markets that otherwise have many potential payers and providers, there may still be instances in which investments, via IC, in the health of a defined population may be viable due to an essentially "captured" (e.g., brandloyal) population. Innovations that appeal to a particular segment of the market may be sustained in the long-run, especially if the incumbent itself is able to generate substantial economies of scale for a model of care that is not only unique in character, but has few competitors, and is an early mover. More generally, funders that have a dominant role in a particular market segment-be that in the provision of a particular type of care or in a given geographical catchment-may also be able to internalize most of the benefits of investments in IC when they have considerable market power and a relatively stable population.

\section{From economic theory to conjectures on the diffusion, effectiveness, and sustainability of IC interventions}

Our main objective is to show that the microeconomic problems of IC interventions that we have discussed so far-particularly externalities and transaction costsare related to the macroeconomic features of health care systems. We focus on these two particular microeconomic features not only because they strike us as of central importance, but also because these phenomena are often closely linked to the other economic considerations described in the preceding Sections (e.g., vertical integration, market structure, and so on).

First, we describe how different types of IC interventions may be characterized in terms of high/low levels of externalities and/or high/low levels of transactions costs. Then, we depict each of the main types of IC intervention in a two-way matrix with the strength of externalities represented in the rows and the size of transaction costs in the columns. Then, we provide a conceptual analysis of different types of IC interventions, highlighting their microeconomic features. Next, we develop a macroeconomic characterization of health systems that also invokes a twoway matrix approach that distinguishes between single and multiple payers (matrix rows) and between vertically and non vertically integrated payers and providers (matrix columns). Finally, we overlay our microeconomic matrix to show the relationships between these macroeconomic arrangements and the likely strength of externalities and transaction costs in different types of health care systems.

Building on the microeconomic factors that were introduced earlier, the theoretical conjecture on the relationship between micro- and macro-features can be expressed as follows.

- IC interventions that have strong externalities and high transaction costs are more likely to be adopted and sustained where there is a vertically integrated single payer.

- IC interventions that have strong externalities but low transaction costs tend to work more efficiently in settings with a single payer, even if it is not vertically integrated.

- IC interventions that have weak externalities and high transaction costs tend still to work efficiently in settings with multiple payers, but are more frequently adopted by payers that are vertically integrated.

- IC interventions that have weak externalities and low transaction costs tend to work efficiently in settings with multiple payers and multiple (non-integrated) providers.

To explain these conjectures, it is useful to provide specific examples of the types of IC interventions that are 
likely to be more (or less) affected by externalities and transaction costs. We consider first a list of examples of interventions from the least- to the most-affected by externality problems:

- Incentives for patients/practitioners or educational programs for individual patients to improve their health, starting from primary prevention: the externality arises due to the fact that patients can choose to switch to other insurers, taking their higher value of health capital (lower prospective costs) to other insurers who, where permitted, may even find it profitable to offer them lower premia or more generous plans to do so.

- Educational programs for practitioners: if educational programs improve the ability of practitioners to manage chronic care patients, it may also lead them to adopt similar clinical approaches for patients enrolled with other insurers. In the longer run, these practitioners and perhaps their supply structures may also switch to other preferred payers, bringing with them their higher level of human capital; once again, competitor insurers may even find it profitable to offer higher levels of remuneration or better working conditions to attract this more productive human capital.

- Coordination programs and other organizational solutions (e.g., clinical pathways): these interventions represent innovations that can be replicated by other payers and, if they are supported by investments in educational programs (paid by the pioneer payer), they are also more likely to be successfully adopted by followers, which may profit from the practitioners' and patients' prior exposure to these programs (i.e., a learning curve effect) without incurring the same fixed costs as the first-mover insurer who launched the innovation;

- Improvements in the use of datasets and AI algorithms: these investments may lead to a greater ability of professionals and practitioners to use their advantages in other data-management systems that are not owned by the innovating insurer. Moreover, due to the obligation to make these data inter-operable, they also provide direct advantages to rival insurers' ability to stratify and segment policy-holders.

Due to non-appropriability, these investments tend to be under-provided by payers in a competitive market and the extent of under-provision may be expected to increase-due to the free-rider problem - the lower is the level of market concentration. By contrast, when there is a single payer, most of the long-term benefits may be internalized, and the extent of under-provision is lessened or eliminated.

Note that here-as in the industrial organization literature on $\mathrm{R} \& \mathrm{D}$ - there is a trade-off between the dynamic efficiency of a single payer that chooses the optimal level of investment to increase the individuals' health capital, reducing the future marginal costs of care managementas of a firm granted an exclusive patent-and the static inefficiency of a single payer that could be either a rentmaximizing private monopolist or a public monopolist with inefficiently high costs (e.g., due to lack of incentives).

Finally, as most of these programs also require investments on the part of providers or of patients, providers may also face problems of non-appropriability. Specifically, since some IC interventions (e.g., investments in ICTs) tend to involve large fixed costs, providers will be more likely to invest in them the larger is the number of practitioners and patients under their care, since this affects the size of the appropriable benefits generated by their investments [26]. For this reason, such IC interventions are more likely to be found, or sustained, in highly concentrated market structures: while this is especially true of health insurance markets, it is also true of health care provision markets.

We now turn to how different levels of transaction costs may affect the working of IC interventions. On the supply side of the market, payers (or insurers) generally have the most to lose from a poorly managed (or fragmented) health care program, due to greater expenditures, the loss of customers, or both. Therefore, payers are often the stakeholders that try to encourage the uptake of IC interventions by health care providers and patients (see, e.g., [27]). Such IC programs often involve the coordination of care by many providers who: have specialized in the delivery of different types of services; have different scopes of practice (e.g., in terms of primary and secondary prevention; and primary, secondary, and tertiary care); and may face financial incentives that are, at least in part, at odds with the payer's objectives.

The most relevant IC investments that give rise to transaction costs are thus:

- Complex clinical pathways: these require coordination between practitioners from several organizations supplying different (diagnostic, specialistic, hospital, and rehabilitation) services and using different information and communication technology (ICT) platforms. In these circumstances, payers are liable to incur high transaction costs on several fronts. First, high costs may arise in bargaining with local providers who, themselves, may have considerable monopoly power. Second, payers may be exposed to lock-in situations which arise due to the need for them to adapt the clinical pathways to specific productive solutions (e.g., in medical homes, hospitals, and nursing homes) that the providers have adopted for various reasons (e.g., profit maximization), but that will lead to inefficient system-level outcomes (from the payer's viewpoint) in the long run. Third, payers face high 
Table 1 Microeconomic characteristics of representative IC interventions

\begin{tabular}{lll}
\hline & Low transaction costs & High transaction costs \\
\hline \multirow{2}{*}{ Weak externalities } & Incentives for patients/practitioners & Complex organizational interventions \\
& Education for patients (self-management) & Fully fledged clinical pathways \\
Strong externalities & Education for practitioners & $\begin{array}{c}\text { ICT platforms for total health popula- } \\
\text { tion management }\end{array}$ \\
& $\begin{array}{c}\text { Simple organizational interventions } \\
\text { Simple AI algorithms to stratify patients }\end{array}$ & \begin{tabular}{c} 
Alternative payment systems \\
\hline
\end{tabular} \\
\hline
\end{tabular}

Table 2 A Taxonomy of the macro-factors of health care systems

\begin{tabular}{|c|c|c|}
\hline & $\begin{array}{l}\text { Vertical integration between payers and providers } \\
\text { Low transaction costs }\end{array}$ & $\begin{array}{l}\text { Vertical dis-integration between payers and providers } \\
\text { High transaction costs }\end{array}$ \\
\hline $\begin{array}{l}\text { Single payer } \\
\text { Weak externalities }\end{array}$ & e.g., Scotland, Italy (most of), Spain (most of), and Canada & $\begin{array}{l}\text { e.g., Sweden, England, Lombardy, Catalonia, and US } \\
\text { Medicare with ACOs }\end{array}$ \\
\hline $\begin{array}{l}\text { Multiple payers } \\
\text { Strong externalities }\end{array}$ & e.g., Kaiser Permanente, Geisinger, and Gesundes Kinzigtal & e.g., US Third-party Insurers, The Netherlands \\
\hline
\end{tabular}

costs of monitoring quality and performance due to large information asymmetries.

- Information and Communications Technology (ICT) standards: these are required to develop more efficient population health strategies, but often need to be adopted by all of the providers involved. Most providers are likely to be locked in their own ICT platforms and therefore be reluctant to make use of one payer's ICT standard that would render them more likely to end up "locked-in" to a contractual relationship with only one payer. Moreover, to adopt one payer's ICT standards is likely to entail the provider losing part of its own information asymmetry advantage, thereby giving away some of its own market (e.g., bargaining) power.

- Alternative payment systems such as risk-adjusted capitation or shared savings (Medicare): these interventions shift the costs of bargaining with all providers that are involved in the IC program onto a single (or a select few) provider(s). These types of payment systems provide sufficient incentives to the accountable provider to reduce the contracting costs by, for instance, buying strategic assets that otherwise increase the transaction costs of running the program (e.g., a hospital's integration of a primary health care network). However, the contractual relationship between the payers and the accountable providers is, in itself, extremely costly to manage (see $[28,29])$ due to asymmetric information problems (e.g., about the quality of the services, performance measures in respect of population health, the risks of adverse selection and rationing, and opportunity costs), thereby demanding further regulatory interventions (e.g., such as those under the US Medicare scheme).

Most of these transaction costs arise due to the joint use of some assets in ICT initiatives. Examples of joint capital include tangible and intangible assets such as supply structures, human capital, professional networks, and ICT platforms. For competing providers, these costs may be managed by vertically integrating those assets, rather than entering into (often incomplete) contractual relationships on the market. If there is competitive pressure, ownership of the assets is typically sought by the stakeholders who have more to lose when they are used inefficiently. Often the payers will end up owning such strategic assets, since they are more likely (than providers) to pursue all of the Triple Aim objectives (i.e., better quality as perceived by patients, lower individual costs, and better population health outcomes to keep under control future costs). All other interest groups-patients, professionals, and providers-are likely to have objectives that are aligned with one, or possibly two, of these objectives.

Our discussion of the microeconomic characteristics of the most diffused types of IC interventions allows us to develop (Table 1) a taxonomy based on the combination of the intensity of the transaction costs (in the columns) and of the externalities (in the rows).

On this basis, we now attempt to illustrate how some of the main macroeconomic features of health care systems combine to define a selective environment that affects the diffusion, effectiveness, and sustainability of different IC interventions (for a similar approach, see [30]). We do so by considering which structural solutions at the macroeconomic level are likely either to ameliorate or exacerbate the problems that were identified above. Our conjecture is that the IC interventions that are more likely to be found in a given macroeconomic environment are those that produce benefits (high quality, high health outcome performances, and low unit costs) while minimizing externality problems (mostly via internalization) and the transaction costs of coordinating several providers (mostly via vertical integration). Table 2 shows how one can set apart dif- 
ferent health systems with respect to the two macrocharacteristics we regard as crucial to work to facilitate or to hinder some of the most widely diffused IC interventions.

Combining the taxonomies set out in Tables 1 and 2 , it is possible to draw the following conjectures on which IC interventions are more likely to be sustained in different health systems given the structural macroeconomic factors that affect the level of externalities and transaction costs:

- Multiple payers without vertical integration (e.g., US Third-party Insurers, The Netherlands): mostly monetary incentives or educational programs for patients, because they give rise to weak externalities and imply low transaction costs. Hence, they can be implemented even in settings where, otherwise, externalities and transactions costs are potentially destructive. Other IC interventions are, prima facie, less likely to be effective or sustainable in such systems.

- Single payers without vertical integration (e.g., Sweden, England, Lombardy, Catalonia, US Medicare with ACOs): simple organizational programs such as educational interventions for practitioners or improvements in ICT and data management to use AI algorithms to stratify patients efficiently into IC programs that best suit their prevention and health care needs. These interventions have relatively low transaction costs that allow for multiple providers, while they can generate large externalities that can be internalized by the single payer. Other, more complex, IC interventions are unlikely to be sustainable in these systems.

- Multiple payers with vertical integration (e.g., Kaiser Permanente, Geisinger, Gesundes Kinzigtal): complex organizational interventions such as complex clinical pathways for segments of the population (e.g., people with various chronic diseases), as the very high transaction costs are kept under control through the ownership of the strategic assets that give rise to asymmetric information, bargaining asymmetries and lock-ins, while the externalities are relatively low. They imply milder externalities (at the patient level) and high transaction costs (which are mitigated by vertical integration).

- Single payers with vertical integration (e.g., Scotland, Italy, Spain, and Canada): alternative payment mechanisms such as risk-adjusted capitation or shared savings schemes, and whole ICT platforms for total health population management can be implemented as the relevant externalities are internalized by the single payer and the transaction costs are kept under control via the ownership of the strategic assets.

\section{Why conjecture, rather than empirical evidence?}

The conceptual arguments developed in the previous Sections can be used to draw some conjectures on the settingsdefined in terms of macroeconomic, or structural, characteristics - in which some IC interventions are likely to be more widely-adopted and sustainable, in the long run. However, attempting to formulate conclusions based on robust empirical evidence is a difficult task for several reasons.

First, empirical research on the effectiveness of IC interventions typically seeks to compare their performance to a specific benchmark, which often is "usual care" (see Bautista et al. 2016 for a survey of the problems in the definition of appropriate performance measures). One of our central points is that "usual care" differs radically between different health care systems, because the structural factors at play in different health care systems are vastly different, as are the resulting incentives, conduct, and performance of health care payers, providers, and (generally) consumers. If this premise is accepted, this raises serious questions about the external validity of results obtained from the introduction of a particular IC intervention in a particular macroeconomic setting. For instance, an IC intervention that leads to better care coordination for people with Type II Diabetes in a health care system with multiple payers and multiple providers, with competitive markets, may improve some indicators of outcomes compared to the status quo, in that system. The same intervention, implemented in a different setting (e.g., with vertical integration of the payer and providers), may not be comparatively effective at all, or worse. Indeed, we argue that the more different are the baseline conditions in the macroeconomic context, the less may be learned from empirical works conducted as quasi-experiments on IC interventions taken from other settings, and vice versa.

Indeed, even when fairly comparable baseline circumstances are available, the exogenous circumstances in which IC interventions are implemented are often still so different as to make it hazardous to draw inferences on applicability of the results to other settings. The external validity problem is indeed a ubiquitous problem in the literature on the effectiveness of interventions to improve the quality or reduce the costs of services in complex institutional settings. However, when those interventions involve adjustments to both the funding and the provision of healthcare services, this problem becomes particularly relevant due to the considerable variety of mechanisms used to finance, commission, pay for, and provide the services in question, as well as the strong influence of each of these segments on each other. For these reasons, what has been proven to work in one setting, might not work in other settings, when if only one of these relevant "structural" characteristics is different. 
As mentioned earlier, even if it is difficult to prove the superiority of a given IC intervention in a given setting, perhaps, one could reasonably take the relative diffusion of such interventions in different settings as evidence that some interventions fit the macroeconomic features of some systems better than others. Even this approach is fraught, though, for several reasons. First, the predominance of particular types of institutional arrangements, whether they are found in "competitive" or NHS-style health care systems, should not be taken as prima facie evidence that only efficient forms of integration and governance survive, in practice. Specifically, unless market failure and public failure are ruled out, the predominance of specific arrangements in these systems seems to us neither a necessary nor a sufficient condition to establish their economic superiority.

Second, when one looks to the scientific literature to find more prevalent IC interventions, publication bias is likely to confound any meta-analysis of what works and what does not. This may not only arise due to bias of the traditional kind (i.e., in which successful interventions are more likely to be published), but also if interventions in particular countries are more likely to be published than in others.

Third, even if there was no systematic country bias, many of the papers on this topic do not provide evidence on how large the IC interventions are, compared to the size of the market for the same healthcare services. Hence, it is very difficult to show evidence about the diffusion of given IC interventions to establish a "functionalist" relationship between the latter and the prevailing structural factors in different countries. Indeed, in the literature, one can find several IC interventions implemented in the USA with strong structural, financial, and organizational elements, but they often share an experimental nature and their size is extremely small in respect of the whole of the corresponding market.

Finally, by contrast, in integrated NHS-type systems, IC interventions are often implemented across the whole system, but such interventions are less often followed by scientific papers that try to assess their performance with respect to the status quo, probably because insufficient econometric identification strategies are typically available to demonstrate causality under those circumstances.

\section{Conclusions and policy implications}

Economists have an important contribution to make to health sector efficiency that extends beyond microeconomic studies of particular interventions in specific macroeconomic settings. Economics has a role in the analysis of IC interventions, because some well-designed and evidence-based interventions that are effective in one health care setting may not be so in macroeconomic environments where, inter alia, the structural characteristics and the incentives that go with these are of a fundamentally different character. Economics provides the basis for choosing, from the menu of IC initiatives that have been tried empirically, those that are most compatible with the incentives of the main actors in the system (chiefly: payers, providers, practitioners, and patients). Rather than focusing on short-term changes to the status quo, by focusing on these considerations, economists may assist policy-makers to effect sustainable changes that enhance health care efficiency and population health.

We have emphasized the importance of considering a number of microeconomic factors-especially externalities and transactions costs- that are likely to affect the success of different types of IC interventions and have proposed that these considerations are closely linked to macroeconomic, or systemic, considerations. We have also noted that these structural characteristics of health care systems affect, by definition, market structures and incentives. These aspects of industrial organization are likely to be critical to the success and the sustainability of different types of IC initiatives in different health care systems. This is especially true given the powerful role that providers and practitioners typically play in the implementation or frustration of measures to integrate patient care: when the incentives these actors face run contrary to the intent of the proposed IC intervention, its sustainable implementation is likely to be difficult. Moreover, the more market power is conferred on these actors by the macroeconomic features of the health care system, the more difficult implementation is likely to be.

We adopted a positive perspective from which we argued that different macroeconomic settings in health care give rise to differences in the likelihood of particular types of IC interventions being effective and sustainable. We also argued that observing the dominance or survival of particular instances of integration or non-integration does not, in itself, constitute a sufficient basis for the conclusion that arrangements that are endemic are necessarily optimal.

Our conjecture was that interventions that give rise to appropriability problems and high transaction costs are more likely to develop in a monopsonistic setting with vertical integration rather than in fragmented and competitive systems. We do not claim that the former settings are more efficient in general, simply that IC interventions of this kind are more likely to survive in them. In health care systems that are heavily focused on equitable health care provision and are characterized by a single payer and heavy vertical integration, complex system-focused IC programs that require strong coordination between providers and professional groups are more likely to pass the cost-benefit test, even if the alignment of incentives on the supply side of the market remains an important hurdle to overcome. An important element of this calculus is that, in such systems, the reference population is stable and the long-run effects of complex IC initiatives can be internalized by the payer. 
Conversely, in health care systems that prioritize competition and consumer choice in health care financing and delivery, the problems of appropriability and high transaction costs mean that complex, system-level IC interventions are likely to be less attractive from an economic viewpoint. In systems of this kind, successful IC programs are likely to be patient-focused and to use simple guidelines and stratification tools, with a more limited focus (than is found in integrated, monopsonistic settings) on providers and practitioners.

\section{References}

1. OECD. Realising the Potential of Primary Health Care, OECD Health Pol Stud. OECD Publishing, Paris (2020)

2. Stokes, J., Panagioti, M., Alam, R., Checkland, K., Cheraghi-Sohi, S., Bower, P.: Effectiveness of Case Management for 'At Risk' Patients in Primary Care: A Systematic Review and Meta-Analysis. PLoS One. 10, doi:https://doi.org/10.1371/journal.pone.01323 40 (2015)

3. Stokes, J., Checkland, K., Kristensen, S.: Integrated Care: Theory to Practice. J Health Serv Res Pol. 21, 282-285 (2016)

4. Smith, S.M., Wallace, E., O'Dowd, T., Fortin, M.: Interventions for Improving Outcomes in Patients with Multimorbidity in Primary Care and Community Settings. Cochrane DB Syst Rev. 14, CD006560. DOI: https://doi.org/10.1002/14651858.CD006560. pub3 (2016)

5. Iovan, S., Lantz, P.M., Allan, K., Abir, M.: Interventions to Decrease Use in Prehospital and Emergency Care Settings Among Super-Utilizers in the United States: A Systematic Review. Med Care Res Rev. 77, 99-111 (2020)

6. Valentijn, P., Schepman, S., Opheij, W., Bruijnzeels, M.: Understanding Integrated Care: A Comprehensive Conceptual Framework Based on the Integrative Functions of Primary Care. Int J Integ Care. 13, 1-12 (2013)

7. Valentijn, P., Vrijhoef, H., Ruwaard, D., Boesveld, I., Arends, R., Bruijnzeels, M.: (2015) Towards an International Taxonomy of Integrated Primary Care: a Delphi Consensus Approach. BMC Fam Pract. 16, 1-15 (2013)

8. O'Connor, P.J.: Normative Data: Their Definition, Interpretation, and Importance for Primary Care Physicians. Fam Med. 22, 307-311 (1990)

9. Schmidt, S., Pardo, Y.: Normative Data. In: Michalos, A.C. (ed.). Encyclopedia of Quality of Life and Well-Being Research, Springer Science+Business Media: Dordrecht. DOI https://doi. org/10.1007/978-94-007-0753-5. 4375-4379 (2014)

10. Colander, D., Su, H.C.: Making sense of economists' positivenormative distinction. J Econ Methodol. 22, 157-170 (2015)

11. Weston, S.C.: Toward a Better Understanding of the Positive/Normative Distinction in Economics. Econ Philos. 10, 1-17 (1994)

12. McWilliams, J., Schwartz, A.: Focusing on High-Cost Patients - The Key to Addressing High Costs? N. Engl. J. Med. 376, 807809 (2017)
13. Moses, H.: Serving Individuals and Populations Within Integrated Health Systems A Bridge Too Far? JAMA-J Am Med Assoc. 321, 1975-1976 (2019)

14. Bator, F.: The Simple Analytics of Welfare Maximization. Am Econ Rev. 47, 22-59 (1957)

15. Coase, R.: The Problem of Social Cost. J Law Econ. 3, 1-44 (1960)

16. Samuelson, P.: The Pure Theory of Public Expenditure. Rev Econ Stat. 36, 387-389 (1954)

17. Frandsen, B., Powell, M., Rebitzer, J.: Sticking points: commonagency problems and contracting in the US healthcare system. Rand J Econ. 50, 251-285 (2019)

18. Hardin, G.: The Tragedy of the Commons. Science. 162, 1243-1248.

19. Lloyd, W.F.: Two Lectures on The Checks To Population, Delivered Before The University Of Oxford in the Michelmas Term 1832. Lloyd, Oxford (1883)

20. Burns, L., Pauly, M.: Transformation of the Health Care Industry: Curb Your Enthusiasm? Milbank Q 96, 57-109 (2018)

21. Cutler, D., Ly, D.: The (Paper)Work of Medicine: Understanding International Medical Costs. J Econ Perpect. 25, 3-25 (2011)

22. Oliver, A.: Incentivising Improvements in Health Care Delivery. Health Econ Policy L. 10, 327-343 (2005)

23. Blomqvist, A.: The Doctor as Double Agent: Information Asymmetry, Health Insurance, and Medical Care. J Health Econ. 10, 411-432 (1991)

24. Wynne, M.: Insurers Owning Hospitals (1980's (sic.) to 1999). The University of Wollongong: Wollongong, https://documents. uow.edu.au/ bmartin/dissent/documents/health/insure_hosps.html (2005). Accessed 8 September 2020.

25. Mathews, A.W.: Physicians, Hospitals Meet Their New Competitor: Insurer-Owned Clinics, The Wall Street Journal, 23 February, https://www.wsj.com/articles/physicians-hospitals-meet-their -new-competitor-insurer-owned-clinics-11582473600 (2020). Accessed 9 September 2020.

26. Agha, L., Frandsen, B., Rebitzer, J.: Fragmented Division of Labor and Healthcare Costs: Evidence from Moves Across Regions. J Public Econ. 169, 144-159 (2019)

27. Hansmann, H.: Ownership of the Firm. J Law Econ Organ. 4, 267-304 (1988)

28. Steenuis, S., Struijs, J., Koolman, X., Ket, J., van der Hijden, E.: Unraveling the Complexity in the Design and Implementation of Bundled Payments: A Scoping Review of Key Elements From a Payer's Perspective. Milbank Q 98(1), 197-222 (2020)

29. Collins, B.: Payments and Contracting for Integrated Care: The False Promise of the Self-Improving Health System. The Kings' Fund, London (2019)

30. Noort, B., Ahaus, K., van den Taart, T., Chambers, N., Sheaff, R.: How Healthcare Systems Shape a Purchaser's Strategies and Actions When Managing Chronic Care. Health Policy 24, 628$638(2020)$

Publisher's Note Springer Nature remains neutral with regard to jurisdictional claims in published maps and institutional affiliations. 